\title{
Salcedo Ávila, Gustavo, Venezuela, Campo de batalla de la guerra fría. Los Estados Unidos y la era de Rómulo Betancourt (1958-1964), Caracas, Fundación Bancaribe, 2017, pp. 294. ISBN: 978-980-7125-22-2
}

Venezuela no es un país relevante dentro del sistema interamericano desde la victoria electoral de Hugo Chávez que dio inicio a la Revolución Bolivariana hace dos décadas. Tampoco es novedosa su reciente consideración como un asunto de Seguridad Nacional para los Estados Unidos. En suma, los fuertes vínculos entre Venezuela y Cuba también tienen un pasado.

La imbricación de estos tres países, cuya centralidad se ha amplificado en la actualidad por la más reciente ofensiva de Estados Unidos que procura restablecer un orden regional en el que cosechó reveses durante los últimos años, tiene una historia. Pese a ello, esto no significa dejar de advertir que asistimos a una proyección evidentemente global de los asuntos internos del país cuyos contornos finales aún no alcanzamos a definir con precisión en medio de una disputa geopolítica en la que existen numerosos intereses en juego.

Una parte de esa historia triangular entre Venezuela, Estados Unidos y Cuba durante un tramo pequeño, pero álgido de la Guerra Fría latinoamericana es la que aborda en su nuevo trabajo el historiador venezolano Gustavo Salcedo Ávila. Se trata de una publicación previamente premiada en el marco de un concurso que desde 2008 se impulsa por parte de la Fundación Bancaribe buscando promover la investigación histórica.

A lo largo de las casi trescientas páginas que lo componen, Salcedo sostiene en forma convincente un fuerte argumento: Venezuela ocupó un lugar central en ese período donde se intensificaron los temores relativos a la seguridad continental. Las fuentes principales que sustentan sus interpretacio-

* Departamento de Historia Americana, Universidad de la República, Montevideo, Uruguay, correo electrónico: robertogarciaferreira@hotmail.com 
nes provienen de tres archivos: la biblioteca presidencial de John F. Kennedy; el archivo del Ministerio de Relaciones Exteriores de la República Bolivariana de Venezuela y el archivo de la Fundación Rómulo Betancourt. A la documentación allí revelada por el autor, se le añade la consulta de numerosas notas de prensa de la época, de documentación desclasificada por el Departamento de Estado - édita e inédita-, de la Agencia Central de Inteligencia de ese mismo país y seis entrevistas con protagonistas venezolanos que ocuparon puestos relevantes - muy cercanos a la toma de decisiones - durante el corte cronológico del que trata el libro.

Munido de esas evidencias empíricas, Salcedo despliega con inteligencia sus argumentos, empleando el relevante material del que dispone con un gran rigor que le permite hilvanar un relato descriptivo por momentos apasionante de una historia en la que sobresalieron numerosos actores, existieron temores e incomprensiones mutuas, amén de otros tantos intereses en colisión.

En ese sentido, resulta compartible presentar a su país como "uno de los principales campos de batalla de la Guerra Fría en América Latina" (p. 28). El capítulo 1, "Un torbellino sacude a Venezuela. Estados Unidos y la Junta de Gobierno" da cuenta de los antecedentes históricos si se quiere estructurales que explican el quiebre que significó el año 1958. Hasta ese momento, y siguiendo un interesante informe del embajador estadounidense en Caracas, "Venezuela ha sido sometida la mayor parte de su historia al dominio de dictadores", algo que explicaba la "ausencia de tradiciones democráticas". Estados Unidos había tenido mucho que ver en eso: su abrazo a los dictadores, histórico, se había profundizado desde el inicio de la Guerra Fría. Aquella colaboración resultó fundamental, a mediados de los años 50, para derrocar el presidente Jacobo Árbenz en Guatemala.

Para entonces, Venezuela ya ocupaba un sitial de privilegio al respecto: desde el golpe contra el presidente constitucional Rómulo Gallegos, en 1948, se había abierto lo que se conoce como "la dictadura", cuyo hombre fuerte, el coronel Marcos Pérez Jiménez, no sólo fue condecorado en el país del Norte, sino que repetidamente había sido presentado como modelo para la región. Así, advierte Salcedo, cuestiones como la democracia y el respeto a los derechos humanos quedaban relegadas a un "segundo plano", o palidecían ante lo realmente importante: que Caracas - "pequeño petroestado"(p. 36) pudiera satisfacer las "necesidades de seguridad nacional" estadounidenses (p. 39).

Regresando al quiebre de 1958, el trabajo reconstruye vívidamente los sucesos que llevaron a huir al dictador el 23 de enero rumbo a la vecina República Dominicana. Ocultar las huellas de aquella amistad no le resultó fácil a la Embajada y al Departamento de Estado: más si se tiene en cuenta que uno de los personajes cordialmente celebrados en los Estados Unidos en 
1954 había sido el temible Pedro Estrada, jefe de Seguridad Nacional venezolana (p. 47). Años de "oportunismo e hipocresía" escribe Salcedo para destallar la difícil coyuntura de entonces, marcada por una dudosa preocupación por la democracia en la "retórica estadounidense hacia Venezuela" (p. 43). El autor trasciende acertadamente el marco nacional señalando que en realidad se trataba de "años de negligencia" hacia América Latina que ahora le estaban pasando "factura a la Casa Blanca" (p. 46). Fue en dicho contexto que tuvo lugar la desventurada gira del vicepresidente Richard Nixon por varios países latinoamericanos. Caracas, como Salcedo notablemente describe, fue el sitio donde el furor antiamericano se expresó más radicalmente, "No hemos olvidado a Guatemala" repetían los jóvenes, entre otras muchas consignas (p. 49). Los "escupitajos" del aeropuerto fueron "tan solo el inicio (y lo más leve) del humillante y peligroso vía crucis" (p. 51). Amén del rico anecdotario del que se da cuenta en el texto, aquellas expresiones entrañaron una cruel paradoja: "Paradójicamente... más logró un grupo de exaltados facinerosos venezolanos que todas las presiones ejercidas previamente en los foros diplomáticos internacionales" (p. 65). Actuando de forma "reactiva" (p. 67) y sin agenda para la región, los sinsabores del viaje y la denominada "Operación Panamericana" lanzada por el presidente de Brasil, J. Kubitsheck, tuvieron eco en Washington, donde Eisenhower fustigó públicamente las dictaduras. Citando a Stephen Rabe, Salcedo concuerda en que aquella fue la "primera vez que un alto funcionario de la administración había recomendado abierta e inequívocamente el sistema de gobierno representativo para América Latina” (p. 78).

El capítulo 2, "Eisenhower y Betancourt. El predominio de la desconfianza y del escepticismo" aborda un momento de transición en Venezuela y América Latina. Era elocuente el cambio de época y no sólo por la irrupción de la Revolución Cubana. Acostumbrado a tratar con los dictadores militares, Estados Unidos debía enfrentar una nueva generación de "políticos progresistas latinoamericanos". "Tendrán que entenderse con nosotros" le escribió el venezolano Betancourt —recién asumido - al costarricense José Figueres (p. 95). No fue sencillo, pues había mutua desconfianza. Fueron diversos empresarios - con fuertes inversiones en la industria petrolera venezolana-, así como funcionarios de la Embajada, quienes añoraron "en voz alta" (p. 92) los tiempos de la dictadura: es que más allá de su claro anticomunismo, parecía existir consenso entre los nuevos gobernantes de que se debía avanzar hacia una participación más amplia del Estado venezolano en las abultadas ganancias derivadas del petróleo (p. 91). Otro elemento de fricción que se describe en este capítulo fue la famosa "Doctrina Betancourt": fríamente recibida en Estados Unidos, poco deseoso a comprometerse seriamente en la promoción de la democracia regional (pp. 100-101). Aunque Rómulo Betancourt tenía una mirada amplia acerca del tema, su 
enemigo principal era el vecino dictador Rafael Trujillo, quien intentó - $\mathrm{y}$ casi consigue - asesinarlo en Caracas. La respectiva investigación de Salcedo en archivos venezolanos le ha servido para documentar las acciones encubiertas emprendidas por Venezuela para intentar socavar las dictaduras regionales (pp. 109-114), apunte referido a este capítulo que también incorpora un fino análisis acerca del frío vínculo entre el venezolano y un joven victorioso Fidel Castro que visita inmediatamente Caracas - entre el 23 y 27 de enero de 1959- para buscar en privado el apoyo material de Betancourt y hacer "una jugada maestra a los gringos" (p. 106).

Las desavenencias y desconfianzas fueron aún mayores en el sensible "tema petrolero", centro del capítulo 3, "El corazón negro de las relaciones bilaterales": "ninguna otra cuestión llegó a ser tan espinosa" escribe el autor (p. 119). El arribo de Betancourt al poder trajo consigo la designación de una figura ya conocida para la embajada y el capital privado: Juan Pablo Pérez Alfonzo. Desde el Ministerio de Minas e Hidrocarburos, sin amilanarse (p. 131), emprendió decididamente el incremento del impuesto sobre la renta, importante golpe a las compañías petroleras y mineras extranjeras afincadas en el país. El Decreto No. 476 aumentaba la participación del Estado venezolano en las ganancias llevándola "del famoso Fifty-Fifty" a un 66-67 por ciento de las ganancias totales. La embajada puso el grito en el cielo: el gobierno no le había consultado antes y, peor aún, el ejemplo podía ser imitado. Las empresas, "capital privado norteamericano", también hicieron sentir fuertemente su voz (p. 123). Los ribetes de dichas protestas, que generaron "una ola de indignación y de nacionalismo", llevaron a que el Departamento de Estado aconsejara a las "compañías de bajar el tono" (p. 124).

En el siguiente apartado del libro, el capítulo 4, Salcedo describe lo que define como "El lento camino hacia la confianza", algo en lo que resultaron fundamentales dos cuestiones: el choque del presidente con los comunistas y la colaboración de Venezuela enfrentando el "radicalismo" cubano (p. 135). Como parte de ese peligroso contexto, en el cual Cuba consideraba a Venezuela como una pieza también clave de su política exterior (p. 158), Estados Unidos se convenció de la necesidad de apoyar a Betancourt como un "aliado del Mundo Libre" (p. 137). Sin embargo, y aunque celebró el "lento divorcio" del venezolano con Castro, Betancourt no habría de ceder ante una operación que pretendiera invadir Cuba: "fue muy claro en advertir a los Estados Unidos de no hacer con Castro lo que hicieron con Jacobo Árbenz" (p. 145).

Los inicios de lo que sería una "relación especial" entre Kennedy y Betancourt ocupan el quinto capítulo. Tal y como el autor copiosamente fundamenta empleando fuentes muy novedosas, existía una "fortísima empatía" entre el venezolano y su par estadounidense recientemente asumido en 1961, 
John Fitzgerald Kennedy (p. 196). De hecho, su elección fue festejada en Miraflores y algunas figuras de estrecha amistad con el presidente venezolano llegaron a ocupar puestos importantes en las decisiones de la Casa Blanca hacia América Latina. Tal y como varios de sus asesores más cercanos le indicaron al joven Kennedy, Venezuela era un "país clave" y necesitaba del "pleno apoyo" estadounidense (p. 168). La hora de la revolución social había llegado a América Latina y para evitarla, Kennedy y sus asesores se convencieron de que debía fortalecerse a figuras como Betancourt, quien podía contribuir decisivamente a canalizar dicho fervor "hacia la centro izquierda". "Una revolución está ocurriendo allá abajo, y yo quiero estar del lado correcto de la misma" fueron las palabras del estadounidense luego de leer una las muchas cartas confidenciales de puño y letra que le hizo llegar el venezolano y que Salcedo incorpora a su análisis (p. 170). La centralidad de América Latina es evidente y ha sido estudiada; menos conocida es la trascendencia de Venezuela que el autor fundamenta convincentemente: Estados Unidos consultaba a Miraflores "antes de actuar" (p. 182) e incluso llegó a existir una "línea telefónica directa" (p. 173).

Parte de los apoyos y de esa necesidad de fortalecer el liderazgo de Betancourt se expresaron en la visita del propio de Kennedy a Caracas - 16 y 17 de diciembre de 1961 - (pp. 186-204), la primera de un presidente de ese país a Venezuela. La visita estuvo precedida de tensiones en el vínculo bilateral - por el tema petrolero- pero también de cooperación en cuanto a la contención de la Revolución Cubana. No se trataba de una decisión sencilla después de conocer el precedente de Nixon (p. 189); sin embargo, Betancourt la necesitaba: el mes anterior, tras la ruptura de relaciones con Cuba, el presidente se encontraba asediado internamente (p. 185). A la vez, Kennedy deseaba discutir personalmente y a fondo la cuestión cubana, con un destacado líder regional, a un mes de celebrarse la reunión de Consulta en Punta del Este, donde habría de expulsarse a Cuba del sistema interamericano. Así lo hicieron. Ambos, no ahorraron elogios mutuos. El presidente anfitrión sostuvo claramente que el visitante "está rectificando toda una larga etapa de ignorancia e incomprensión de los problemas de América Latina; de fe puesta en las dictaduras que pasaban y no en los pueblos que quedaban". Pese al "cólico estomacal" que sufrió Kennedy en pleno vuelo tras un almuerzo típico venezolano en Maracay —que obligó a desviar el helicóptero presidencial hacia una base militar para que el estadounidense pudiera ir al baño- (p. 195), éste valoró la hospitalidad y calidez con que fue recibido (p. 202). Las conversaciones privadas de alto nivel derivaron en acuerdos importantes sobre dos de los tres puntos tratados: Cuba y República Dominicana. La cuestión petrolera, más allá de la cordialidad, no tuvo avances importantes. Poco más adelante otro motivo de fricción fueron los golpes militares acaecidos en Argentina y Perú. Venezuela, que reimpulsó 
nuevamente su "doctrina Betancourt", procuró regionalizarla sin éxito, algo para lo cual tampoco contó con la ayuda de Kennedy.

El año 1963 trajo otras instancias relevantes en el vínculo bilateral de Estados Unidos con Venezuela, algo de lo cual se ocupa el capítulo 6, "De la cumbre al ocaso de la relación especial". Allí se incluyen sendos relatos explicativos sobre el comúnmente delicado tema petrolero, otra vez en el tapete a inicio de ese año por la política discriminatoria de Estados Unidos que no comprendió a Venezuela entre los países que serían considerados exentos de las restricciones a la importación de petróleo que el Congreso estadounidense aprobó. La ausencia de un trato preferencial hacia Venezuela pese a la "relación especial" entre ambos presidentes y a la probada colaboración del país sudamericano en los esfuerzos por aislar a Cuba motivó el "mayor malentendido" entre ambos gobiernos (p. 227). Al igual que en el pasado, las reuniones de alto nivel poco pudieron avanzar, incluso mediando la visita oficial de cinco días de Rómulo Betancourt a Estados Unidos, del 18 al 23 de febrero de 1963. "Nosotros somos... grandes admiradores suyos. Deseamos que los Estados Unidos sean identificados con líderes como usted, no solo en Venezuela... sino a lo largo de este hemisferio" y "ese es el gran desafío que enfrentamos" sostuvo Kennedy (pp. 236-237). Parte de ese reconocimiento se pudo observar durante la última reunión de trabajo, cuando Kennedy le pidió al visitante que repasara la "situación política latinoamericana": "por más de una hora los funcionarios estadounidenses escucharon y tomaron nota como jóvenes estudiantes ante lo que decía el experimentado líder" sobre Juan José Arévalo, Juan Bosch, Salvador Allende y Eduardo Frei, entre otros (pp. 242-243).

Pero los golpes de estado, otra vez, habrían de colocar a ambos mandatarios en filas opuestas. Guatemala, Ecuador, República Dominicana y Honduras fueron escenarios de cambios de gobierno impulsados por las botas militares. El "gorilismo" — como comenzó a hablarse en ese momentodaba sus primeros pasos en el marco de la Doctrina de la Seguridad Nacional. Betancourt quiso imponer su visión relativa al no reconocimiento de ese tipo de salidas autoritarias no solamente como parte de su ya conocida política internacional, sino también porque él mismo se encontraba asediado internamente y si algo deseaba era alejar con ello a los militares venezolanos de emprender un golpe contra él mismo. Betancourt, empleando sus canales directos, le hizo llegar otra carta personal a Kennedy: "[1]o que han logrado y lograrán no es erradicar el comunismo, sino crear en los pueblos un sentimiento de frustración y de falta de fe en el sistema democrático" (p. 252). Entre los asedios que también debía sortear el propio Betancourt, hubo otro que apuntaba hacia La Habana, desde donde se embarcaron armas buscando instalar un foco guerrillero en el país. Las armas fueron descubiertas y los oficiales de la CIA llevaron hasta el presidente uno de los rifles enseñándole 
dónde había sido "defectuosamente lijado" el escudo de Cuba. "Creo que ya lo atrapamos" dijo el presidente Kennedy refiriéndose a Fidel (p. 258). Sin embargo, su asesinato en Dallas, pocas horas después, "puso en un lejano segundo plano el problema de las armas cubanas", subraya Salcedo (p. 259). La "muerte de un amigo" era también el ocaso de la relación especial.

En definitiva, Venezuela, campo de batalla de la guerra fría, constituye el acercamiento a un momento "crucial" de la historia venezolana y hemisférica, algo que aún mantiene vigencia y fuerte proyección en el presente, indica Salcedo (pp. 278-279). Entre los muchos aciertos de la obra debe destacarse su contribución a pensar en términos de larga duración la preponderancia del peso de la industria petrolera en el país y lo que parece ser una crónica debilidad de la institucionalidad venezolana que según se documenta constituye un elemento estructural. Aunque el foco principal es la relación bilateral entre Estados Unidos y Venezuela atendiendo fundamentalmente a documentación estadounidense, debe agregarse que el autor nunca pierde de vista el orden global y regional. A la vez, las escasamente conocidas fuentes venezolanas que también dan sustento a los argumentos básicos del libro, sin duda constituyen un bienvenido aporte para proseguir en la labor de descentrar los debates de la historia de la Guerra Fría latinoamericana que, cada vez parece más claro, no debe pensarse exclusivamente desde el norte global, sino en diálogo con lo que producimos desde el sur gracias a las nuevas fuentes ahora disponibles. Tal y como esta investigación deja al descubierto, Betancourt y su país incidieron directamente en la agenda de la Guerra Fría y contribuyeron en forma importante a moldear o acaso matizar la visión que desde Estados Unidos se trazaba muy habitualmente acerca de esta parte del mundo. Nuevamente, como ha subrayado hace tiempo el historiador Max P. Friedman, el trabajo de Salcedo impone "retirar las marionetas": aunque Betancourt fue un aliado regional importante, la tesis de un gobierno "subyugado" al de Estados Unidos y "entregado" a los intereses privados de sus compañías es algo "alejado de la verdad" subraya el autor (p. 28). 